\title{
Developing Pedotransfer Functions for Estimating Field Capacity and Permanent Wilting Point Using Fuzzy Table Look-up Scheme
}

\author{
Ali Keshavarzi (Corresponding author) \\ Department of Soil Science Engineering, University of Tehran \\ P.O.Box: 4111, Karaj 31587-77871, Iran \\ Tel: 98-261-223-1787_E-mail: alikeshavarzi@ut.ac.ir, aliagric@gmail.com \\ Fereydoon Sarmadian \\ Department of Soil Science Engineering, University of Tehran \\ P.O.Box: 4111, Karaj 31587-77871, Iran \\ Tel: 98-261-223-1787 E-mail: fsarmad@ut.ac.ir \\ Reza Labbafi \\ Department of Agricultural Machinery Engineering, University of Tehran \\ P.O.Box: 4111, Karaj 31587-77871, Iran \\ Tel: 98-261-280-8138_E-mail: Rezalabbafi@ut.ac.ir \\ Abbas Ahmadi \\ Member of Scientific Board, Islamic Azad University, Arak Branch, Iran \\ E-mail: abahmadi@gmail.com
}

\begin{abstract}
Study of soil properties like field capacity (F.C) and permanent wilting point (P.W.P) plays important roles in study of soil moisture retention curve. Pedotransfer functions (PTFs) provide an alternative by estimating soil parameters from more readily available soil data. In this study, a new approach is proposed as a modification to a standard fuzzy modeling method based on the table look-up scheme. 70 soil samples were collected from different horizons of 15 soil profiles located in the Ziaran region, Qazvin province, Iran. Then, fuzzy table look-up scheme was employed to develop pedotransfer functions for predicting F.C and P.W.P using easily measurable characteristics of clay, silt, O.C, S.P, B.D and $\mathrm{CaCO}_{3}$. In order to evaluate the models, root mean square error (RMSE) and $\mathrm{R}^{2}$ were used. The value of RMSE and $\mathrm{R}^{2}$ derived by fuzzy table look-up scheme for F.C and P.W.P were $(1.65,0.87)$ and $(1.03,0.83)$, respectively.
\end{abstract}

Keywords: Field capacity, Permanent wilting point, Pedotransfer functions, Fuzzy Table Look-up Scheme

\section{Introduction}

Field capacity is defined as the maximum water content in a soil two to three days after being wetted and free drainage is negligible. Wilting point is defined as the soil water content where leaves of sunflower plants wilt continuously (Cavazza et al., 2007). Soil water contents at field capacity and wilting point are used to calculate the water depth that should be applied by irrigation (Givi et al., 2004), and to determine water availability, which is a crucial factor in assessing the suitability of a land area for producing a given crop (Sys et al., 1991). The development of models simulating soil processes has increased rapidly in recent years. These models have been developed to improve the understanding of important soil processes and also to act as tools for evaluating agricultural and environmental problems. Consequently, simulation models are now regularly used in research and management (Minasny and McBratney, 2002). F.C, P.W.P and cation exchange capacity (CEC) are among the most important soil properties that are required in soil databases (Manrique et al., 1991), and are used as inputs in soil and environmental models (Amini et al., 2005; Keller et al., 2001). However, soil properties can be highly variable spatially and temporally, and measuring them is both time consuming and expensive. As a result, the most difficult and expensive step towards the process of environmental modeling is the collection of data. The term pedotransfer function (PTF) was coined by Bouma (1989) as translating available data (those we have) 
into useful information (what we need). The most readily available data come from soil survey, such as field morphology, texture, structure and $\mathrm{pH}$. Pedotransfer functions add value to this basic information by translating them into estimates of other more laborious and expensively determined soil properties. These functions fill the gap between the available soil data and the properties which are more useful or required for a particular model or quality assessment.

The two common methodology used to develop PTFs are multiple-linear regression (MLR) and artificial neural network (ANN) modeling techniques. MLR analysis is generally used to find the relevant coefficients in the model equations. Often, however, models developed for one region may not give adequate estimates for a different region (Wagner et al., 2001). A more advanced approach to model PTFs is to make use of ANN technique (Schaap et al., 1998). ANN offers a fundamentally different approach for modeling soil behavior. Many studies related to modeling various soil parameters using different types of PTFs has been conducted. Schaap et al. (1998) developed some functions for estimation of the different parameters of van Genuchten, van Genuchten- Mualem, and Gardner equations by means of ANNs. Their results showed that with increasing the number of input data, the accuracy of functions would enhance. Omid et al. (2005) adapted ANN to model sequent depth and jump length, both important parameters in the design of stilling basins with hydraulic jumps. 16 configurations, each with different number of hidden layers and/or neurons, were evaluated. The optimal models were capable of predicting sequent depth and jump length for a wide range of conditions with a mean square error (MSE) of 10\%. A comparative study among MFNN and empirical models was also carried out. They found ANN models performed superior than regression models. Vos et al. (2005) used 12 PTFs and Brazilian's database for prediction of bulk density. Their results showed that the separation of subsoil data from topsoil data did not increase the accuracy of prediction. Najafi and Givi (2006) used the ANNs and PTFs methods for prediction of soil bulk density. They pointed out that the ANNs are able to predict the soil bulk density better than the PTFs. Jain and Kumar (2006) indicated that the ANN technique can be successfully employed for the purpose of calibration of infiltration equations. They had also found that the ANNs are capable of performing very well in situations of limited data availability. In contrast Merdun et al. (2006) pointed out that although the differences between regression and ANN models were not statistically significant, regression predicted point and parametric variables of soil hydraulic parameters better than ANN.

Fuzzy inference is the process of formulating the mapping from a given input to an output using fuzzy logic. The mapping then provides a basis from which decisions can be made, or patterns discerned. Fuzzy inference systems have been successfully applied in fields such as automatic control, data classification, decision analysis, expert systems, and computer vision (Sun, 2009). Because of its multidisciplinary nature, fuzzy inference systems are associated with a number of names, such as fuzzy-rule-based systems, fuzzy expert systems, fuzzy modeling, fuzzy associative memory, fuzzy logic controllers, and simply (and ambiguously) fuzzy systems. Fuzzy set theory has been widely used in soil science for soil classification and mapping, land evaluation, fuzzy soil geostatistics, soil quality indices (Chang and Burrough, 1987; Burrough, 1989; Zhu et al., 1996; McBratney and Odeh, 1997; McBratney et al., 2003; Zhang et al., 2004; Lagacherie, 2005). McBratney and Odeh (1997) showed the potential of fuzzy set theory in soil science, such as mapping and numeric classification, landuse evaluation, modeling and simulation of physical processes. Metternicht and Gonzalez (2004) presented a fuzzy exploratory model for the prediction of soil erosion hazards. Sadiq and Rodriguez (2004) evaluated and predicted the performance of slow sand filters using fuzzy rule-based modeling. Enea and Salemi (2001) and Klingseisen et al. (2007) used fuzzy logic for evaluating environmental impacts. Tayfur et al. (2003) studied a fuzzy logic algorithm to estimate sediment loads from bare soil surfaces. Predicting the mean sediment loads from experimental runs, the performance of the fuzzy model was compared with that of the artificial neural networks (ANNs) and the physics-based models. The results of showed revealed that the fuzzy model performed better under very high rainfall intensities over different slopes and over very steep slopes under different rainfall intensities. Tran et al. (2002) developed a fuzzy-rule based model to improve the performance of the revised universal soil loss equation (RUSLE). Their approach consisted of two approaches: (1) Multi-objective fuzzy regression (MOFR); and (2) Fuzzy rule-based modeling (FRBM). Zhu et al. (2010) presented a method to construct fuzzy membership functions using descriptive knowledge. Construction of fuzzy membership functions is accomplished based on two types of knowledge: 1) knowledge on typical environmental conditions of each soil type and 2) knowledge on how each soil type corresponds to changes in environmental conditions. In this study, a new approach is proposed as a modification to a standard fuzzy modeling method. This new method takes randomness into account by considering the statistical properties of training data set. The method discussed here is called table look-up scheme. The idea is based on all available input-output data pairs (Jang et al., 1997; Liu et al., 2003), a rule base will be build. Then the unknown system between the input-output can be approximated using this rule base. 
Hence, the present study was carried out with objective to evaluate of fuzzy table look-up scheme for estimating F.C and P.W.P using some easily measurable soil parameters in Ziaran region.

\section{Materials and methods}

\subsection{Site description}

The study was carried out in Ziaran region, Qazvin province in Iran. The research commenced in 2008 and ended in 2009. The land investigated in the research is located between latitudes of $35^{\circ} 58^{\prime}$ and $36^{\circ} 4^{\prime} \mathrm{N}$ and between longitudes of $50^{\circ} 24^{\prime}$ and $50^{\circ} 27^{\prime} \mathrm{E}$ which has the area about 5121 hectares. The average, minimum and maximum heights points of Ziaran district are 1204, 1139 and 1269 meters above sea level, respectively (Fig1). The soil moisture and temperature regimes of the region by means of Newhall software are Weak Aridic and Thermic, respectively. Based on soil taxonomy (USDA, 2010), this region has soils in Entisols and Aridisols orders.

\subsection{Data collection and soil sample analysis}

After preliminary studies of topographic maps (1:25000), using GPS, studying location was appointed. 70 soil samples were collected from different horizons of 15 soil profiles located in Ziaran region in Qazvin Province. Measured soil parameters included texture (determined using Bouyoucos hydrometer method), Organic Carbon (O.C) was determined using Walkley-Black method (Nelson and Sommers, 1982). The clod method (Blake and Hartge, 1986) was used to determine bulk density (B.D). The moisture contents at field capacity and wilting point were determined with a pressure plate apparatus at -33 and $-1500 \mathrm{kPa}$, respectively (Cassel and Nielsen, 1986). Water saturation percentage (S.P) and $\mathrm{CaCO}_{3}$ content were determined using standard methods (Sparks et al., 1996).

\subsection{Membership functions and Fuzzy Table Look-up Scheme}

A general fuzzy system has the components of fuzzification, fuzzy rule base, fuzzy output engine, and defuzzification. Fuzzification converts each piece of input data to degrees of membership by a look-up in one or more several membership functions. The key idea in fuzzy logic is the allowance of partial belongings of any object to different subsets of a universal set, instead of completely belonging to a single set. Partial belonging to a set can be described numerically by a membership function, which assumes values between 0 and 1 inclusive. Intuitions, inference, rank ordering, angular fuzzy sets, neural networks, genetic algorithms, and inductive reasoning can be among many ways to assign membership values or functions to fuzzy variables. Especially, the intuitive approach is used rather commonly because it is simply derived from the innate intelligence and understanding of human beings. Fuzzy membership functions may take on many forms, but in practical applications simple linear functions such as triangular ones are preferable (Tayfur et al., 2003). MFs for the corresponding inputs are recommended by MATLAB (7.8) as Gaussian membership function. There are five steps in generating fuzzy rules with fixed membership functions. Consider the design of a fuzzy system with two inputs $\left(\mathrm{x}_{1}, \mathrm{x}_{2}\right)$ and one output $(\mathrm{y})$ system. Further, there are $n$ data points in the training set.

Step1: Define the fuzzy partition of the input and output variables.

Step2: Generate one fuzzy rule for each of the $n$ input-output pairs:

This results in the initial fuzzy rule base (Eq.1) (Mendel, 2001; Liu et al., 2003):

$$
\left(x_{1}^{p}, x_{2}^{p}, y^{p}\right) \Rightarrow \text { Fuzzy Rule } p=1,2, \ldots, n
$$

From this input-output pair, one fuzzy rule can be generated. One may be reminded of the facts that the fuzzy sets may overlap. Now the question is how to assign the appropriate membership functions to the variables in each data pair. The common practice is that the fuzzy variable is assigned the membership function that produces the maximum membership value.

Step 3: Calculate the degree for each fuzzy rule resulted from rules:

The number of fuzzy rules generated by the input-output pairs is usually large. Inconsistent and redundant rules are inevitable. One is then confronted with the task of eliminating the inconsistency and redundancy.

Step 4: Create the final fuzzy rule base by removing inconsistent and redundant rules:

In the standard approach, the rule having the largest degree is adopted. As an improvement, a new selection approach is proposed here to remove inconsistency and redundancy. The notion of reliability factor is introduced. Specifically, for each given set of $k$ rules with the same antecedent parts, the reliability factor is defined as (Liu et al., 2003): 


$$
\text { Reliability Factor }(R F)=\frac{K_{1}}{K}
$$

Where:

$\mathrm{k}_{1}=$ Number of redundant rules,

$\mathrm{k}=$ Total number of the redundant and inconsistent rules having the same antecedent part.

The reliability factor is then used as a weighting factor for computing the effective degree for each rule degree as follows (Liu et al., 2003):

$$
\text { Effective Degree }\left(\mathrm{D}_{\text {eff }}\right)=D^{*} R F
$$

Table 1 shows the reliability factors for the inconsistent and redundant rules itemized. The final fuzzy rule-base can now be compiled by choosing the rules with the largest effective degrees. For the redundant and inconsistent rules in table 1, the effective degree is given by (Liu et al., 2003):

$$
D_{\text {eff }}(\max )=\max \left(D_{\text {eff }(i)}\right), \quad i=1,2, \ldots, n
$$

Where: $D_{\text {eff }}=$ effective degree, and $\mathrm{n}$ is the number of membership function.

Step 5: Determine the overall fuzzy system:

Up to this point, the membership functions are defined in step1 and the fuzzy rule-base is compiled in step 4. Fuzzy interference is performed next. In this paper, Mamdani's inference scheme is adopted for its simplicity (Figures 2 and 3). In carrying out fuzzy inference (reasoning), mathematical operations on the membership functions are invariably required. Any T-norm or S-norm can be used to define the operations involving membership function. In addition, any defuzzification scheme such as the centroid method can be selected. This essentially completes the design procedure in modeling a fuzzy system. In summary, the modified table look-up scheme offers an effective method for removing inconsistency and redundancy in the process of assembling fuzzy rules. In this study, MATLAB 7.8 software was used for the design and testing of fuzzy table look-up scheme.

\subsection{Performance criteria}

The performance of the models was evaluated by a set of test data using the root mean square error (RMSE) and the coefficient of determination $\left(\mathrm{R}^{2}\right)$ between predicted and measured values. The RMSE is a measure of accuracy and reliability for calibration and test data sets (Wösten et al., 1999) and is defined as:

$$
R M S E=\sqrt{\frac{1}{n} \sum_{k=1}^{n}\left(z_{o}-z_{p}\right)^{2}}
$$

Where: $Z_{\mathrm{o}}$ is observed value, $Z_{\mathrm{p}}$ is predicted value, and $\mathrm{n}$ is number of samples.

\section{Results and discussion}

\subsection{Data summary statistics}

Data summary of training and testing sets are presented in tables 2 and 3, respectively. Data subdivided into two sets: $20 \%$ of the data for testing and the remaining $80 \%$ of the data were used for training or calibrating. Some soil parameters including clay, silt, O.C, S.P, B.D and $\mathrm{CaCO}_{3}$ contents were input data for prediction of F.C and P.W.P. Simple linear correlation coefficients (r) among F.C, P.W.P and independent variables were also calculated (Table 4). As Table 4 illustrates correlations among S.P, clay and F.C and also, among S.P, clay and P.W.P were positive and highly significant. For example the correlation coefficients between F.C and clay content $(r=0.75)$ is rather similar to the between P.W.P and clay content $(r=0.71)$. Also, the correlation coefficient between B.D and O.C content $(r=-0.58)$ is rather more than between B.D and S.P $(r=-0.27)$. However with regarding to these correlation coefficients, both of them are suitable for developing PTFs for prediction of F.C and P.W.P in soils of Ziaran region. Similarly these correlations between F.C and S.P $(r=0.95)$ and also, between P.W.P and S.P $(r=0.90)$ were positive and significant. The correlation between $\mathrm{CaCO}_{3}$ and clay content $(\mathrm{r}=0.59)$ and between $\mathrm{CaCO}_{3}$ and $\mathrm{SP}(\mathrm{r}=0.49)$ were relatively high. In addition with regarding to this table it is clear that B.D is negatively correlated with F.C $(\mathrm{r}=-0.29)$ and P.W.P $(\mathrm{r}=-0.23)$.

\subsection{Developing PTFs using Fuzzy Table Look-up Scheme}

Fuzzy rule-base contains fuzzy rules that include all possible fuzzy relations between inputs and outputs. These 
rules are expressed in the IF-THEN format. In the fuzzy approach there are no mathematical equations and model parameters, however, all the uncertainties and model complications are included in the descriptive fuzzy inference procedure in the form of IF-THEN statements (Tayfur et al., 2003). In this study, 50 fuzzy rules relating the clay, silt, O.C, S.P, B.D and $\mathrm{CaCO}_{3}$ contents to F.C and P.W.P were inferred from the training data. The antecedent part of the rule (the part starting with IF, up to THEN) included a statement on the clay, silt, O.C, S.P, B.D and $\mathrm{CaCO}_{3}$ contents while the consequent part (the part starting with THEN, up to the end) included a statement on F.C and P.W.P. For example 'IF the (Clay is Very Low) and (Silt is Very Low) and (O.C is Very Low) and $\left(\mathrm{CaCO}_{3}\right.$ is Very Low) and (S.P is Very Low) and (B.D is High), THEN the (F.C is Very Low)'. Tables 5 and 6 summarize the fuzzy rules constructed in this study. Fuzzy inference engine takes into account all the possible fuzzy rules in the fuzzy rule base and learns how to transform a set of inputs to corresponding outputs. A general structure of fuzzy system is demonstrated in figure 4. In the main, each fuzzy system consists of three main sections, fuzzifier, fuzzy data base and Defuzzifier. At first, input information is made as fuzzy data after bypassing the fuzzifier sections, in which the precise amount value becomes as fuzzy value by membership functions (Figure 5). Defuzzification converts the resulting fuzzy outputs from the fuzzy inference engine to a number. There are several defuzzification methods, such as the weighted average, maximum membership, average maximum membership, and center of gravity, etc. In this study, the 'lom' method is employed. Later, fuzzy parameters are entered to the fuzzy data base. Fuzzy data base includes two main sections, fuzzy rule-base and inference engine. In fuzzy rule-base, rules related to fuzzy propositions are described. Thereafter, analysis operation is applied by fuzzy inference engine.

There are two main fuzzy inference engine-Sugeno and Mamdani- for this purpose. In this paper, Mamdani's inference scheme is adopted for its simplicity (Figures 2 and 3 ) and used for predicting mentioned parameters. Then, the optimum structures of fuzzy table look-up scheme by means of coefficient of determination and RMSE criteria were determined. The value of RMSE and $\mathrm{R}^{2}$ derived by fuzzy table look-up scheme for F.C and P.W.P were $(1.65,0.87)$ and $(1.03,0.83)$, respectively (Table 7$)$. The scatter plot of the measured against predicted F.C and P.W.P for the test data set are given in figures 6 and 7. So that according to this diagrams, the best fitted line has the angle of near to $45^{\circ}$ that shows the high accuracy of estimation by fuzzy table look-up scheme. Liu et al. (2003) found that the modified table look-up scheme can predict the time series more accurately when noise was added to the time series. Akbarzadeh et al. (2009) in their study showed that a hybrid method (ANN and Fuzzy model) predicted soil CEC with very high accuracy. Burrough et al. (1992) demonstrated that fuzzy classification produced a superior number of available areas for agriculture compared to conventional Boolean classification. Zorluer et al. (2010) investigated the application of a fuzzy rule-based method for determination of clay dispersibility. In this study, a fuzzy logic approximation method was developed to combine the different results of the double hydrometer, pinhole, Na (\%)-TDS and ESP-CEC methods into a single value. This new method was applied to the dispersibility test results of 29 samples, and it gave more reliable and objective results for identifying the dispersibility of the clay soil.

Fernández et al. (2009) worked with fuzzy rules based on classification systems using a preprocessing step to deal with class imbalance. Their aim was to analyze the behavior of fuzzy rule-based classification systems in the framework of imbalanced datasets through the application of an adaptive inference system with parametric conjunction operators. The empirical results showed that the use of these parametric conjunction operators resulted in a higher performance for all datasets with different imbalanced ratios. As figures 6 and 7 showed fuzzy table look-up scheme predicted soil properties with relatively high accuracy $\left(\mathrm{R}^{2}=0.87\right.$ and 0.83$)$. In practice, it is extremely difficult to saturate a soil with water because of air trapping (Hillel, 1998; Mermoud and $\mathrm{Xu}, 2006$ ). Tamari et al. (1996) predicted poorly $\mathrm{K}$ values at matric potentials of -10 and $-25 \mathrm{kPa}$ with both methods of ANN and regression, and they suggested that soil samples should be classified based on their texture as coarse, medium and fine. Therefore, difficulty in measuring soil hydraulic properties in heterogeneous soils might cause this prediction. Analysis of the ANN parameters suggested that more input variables were necessary to improve the prediction of unsaturated hydraulic conductivity (Tamari et al., 1996; Mermoud and Xu, 2006). The differences between the field and laboratory determination of water retention data might be associated to the insufficient representation of large pores in the laboratory, sample disturbance and spatial variation, hysteresis, and scale effects related to the sample size (Field et al., 1984; Shuh et al., 1988; Mermoud and Xu, 2006). Pachepsky and Rawls (2003) found significant differences between the field and laboratory volumetric water contents for coarse-, intermediate-, and fine-textured soil horizons. Therefore, measurement errors might cause poor prediction of the parameters.

\section{Conclusion}

In this study fuzzy table look-up scheme was employed to develop pedotransfer functions for predicting F.C and 
P.W.P using easily measurable characteristics of clay, silt, O.C, S.P, B.D and $\mathrm{CaCO}_{3}$. Summary of conclusion can be stated as follows:

1) Fuzzy inference system is a rule-based system consists of three conceptual components. There are: a rule base, contains fuzzy IF-THEN rules, a database, defines the membership function and an inference system, combines the fuzzy rules and produces the system results.

2) First phase of fuzzy logic modeling is the determination of membership functions of input-output variables, second is the construction of fuzzy rules and the last is the determination of output characteristics, output membership function and system results.

3) With regarding to the evaluation criteria, the results of this study revealed that the fuzzy table look-up predicted soil properties with relatively high accuracy $\left(R^{2}=0.87\right.$ and 0.83$)$.

4) However, due to difficulties of direct measurement of soil parameters, we recommend using of neuro-fuzzy models in the future studies for obtaining the logical equations of other soil parameters, especially soil hydraulic properties, in each area and also we recommended testing fuzzy table look-up for predicting F.C and P.W.P in other regions.

\section{Acknowledgement}

The financial support provided by the University of Tehran, is gratefully acknowledged. Also, we would like to gratefully thank all the members of the soil science laboratory of the University of Tehran for providing the facilities to carry out this work and for their suggestions.

\section{References}

Akbarzadeh, A., Taghizadeh Mehrjardi, R., Rahimi Lake, H., \& Ramezanpour, H. (2009). Application of Artificial Intelligence in Modeling of Soil Properties (Case Study: Roodbar Region, North of Iran). Environ Research J., 3(2), 19-24.

Amini, M., Abbaspour, K. C., Khademi, H., Fathianpour, N., Afyuni, M., \& Schulin, R. (2005). Neural network models to predict cation exchange capacity in arid regions of Iran. Eur. J. Soil Sci., 53, 748-757.

Blake, G. R. \& Hartge, K. H. (1986). Particle density. In: Klute, A., (Eds.), Methods of soil analysis, Part 1, Agron Monogr 9, ASA, Madison, WI, USA. pp. 377-382.

Bouma, J. (1989). Using soil survey data for quantitative land evaluation. Advances in Soil Science, 9, 177-213.

Burrough, P. A. (1989). Fuzzy mathematics methods for soil survey and land evaluation. Journal of Soil Science, 40, 447-492.

Burrough, P. A., MacMillian, R. A., \& Van Deusen, W. (1992). Fuzzy classification methods for determining land suitability from soil profile observations and topography. Journal of Soil Science, 43, 193-210.

Cassel, D. K. \& Nielsen, D. R. (1986). Field capacity and available water capacity. In: Klute, A. (Eds.), Methods of Soil Analysis. Part 1, 2nd ed. Agron Monogr 9, ASA and SSSA, Madison, WI, USA. pp. 901-926.

Cavazza, L., Patruno, A. \& Cirillo, E. (2007). Field capacity in soils with a yearly oscillating water table. Biosystems Engineering, 98, 364-370.

Chang, L., \& Burrough, P. A. (1987). Fuzzy reasoning: a new quantitative aid for land evaluation. Soil Survey and Land Evaluation, 7, 69-80.

Enea, M., \& Salemi, G. (2001). Fuzzy approach to the environmental impact evaluation. Ecological Modelling, 136, 131-147.

Fernández, A., Jesus, M. J., \& Herrera, F. (2009). On the influence of an adaptive inference system in fuzzy rule based classification systems for imbalanced data-sets. Expert Systems with Applications, 36, 9805-9812.

Field, J. A., Parker, J. C. and Powell, N. L. (1984). Comparison of field- and laboratory measured and predicted hydraulic properties of a soil with macropores. Soil Sci., 138: 385-396.

Givi, J., Prasherb, S. O. \& Patel, R. M. (2004). Evaluation of pedotransfer functions in predicting the soil water contents at field capacity and wilting point. Agricultural Water Management, 70, 83-96.

Hillel, D. (1998). Environmental Soil Physics. Academic Press, New York, USA.

Jain, A., \& Kumar, A. (2006). An evaluation of artificial neural network technique for the determination of infiltration model parameters. Appl. Soft Comput., 6, 272-282.

Jang, J. S. R., Sun, C. T., \& Mizutani, E. (1997). Neuro-Fuzzy and Soft Computing: A Computational Approach 
to Learning and Machine Intelligence. Prentice-Hall, Inc., Upper Saddle River, NJ, USA.

Keller, A., Von Steiger, B., Vander Zee, S. T. \& Schulin, R. (2001). A stochastic empirical model for regional heavy metal balances in agroecosystems. Journal of Environmental Quality., 30, 1976-1989.

Klingseisen, B., Metternicht, G., \& Paulus, G. (2007). Geomorphometric landscape analysis using a semi-automated GIS-approach. Environmental Modelling and Software, In Press.

Lagacherie, P. (2005). An algorithm for fuzzy pattern matching to allocate soil individuals to pre-existing soil classes. Geoderma, 128, 274-288.

Liu, X., Kwan, B. W., \& Foo, S. Y. (2003). Time Series Prediction Based on Fuzzy Principles. Proc. 'Huntsville Simulation' Conf, October 8, Huntsville, AL.

Manrique, L. A., Jones, C. A., \& Dyke, P. T. (1991). Predicting cation exchange capacity from soil physical and chemical properties. Soil Sci. Soc. Am. J., 50, 787-794.

McBratney, A. B., \& Odeh, I. O. A. (1997). Application of fuzzy sets in soil science: fuzzy logic, fuzzy measurements and fuzzy decisions. Geoderma, 77, 85-113.

McBratney, A. B., Mendonca, M. L., \& Minansy, B. (2003). On digital soil mapping. Geoderma, 117, 3-52.

Mendel, J. M. (2001). Rule-Based Fuzzy Logic Systems. Prentice-Hall, Inc., Upper Saddle River, NJ, USA.

Merdun, H., Cinar, O., Meral, R. \& Apan, M. (2006). Comparison of artificial neural network and regression pedotransfer functions for prediction of soil water retention and saturated hydraulic conductivity. Soil Till Res., 90, 108-116.

Mermoud, A. \& Xu, D. (2006). Comparative analysis of three methods to generate soil hydraulic functions. Soil Till Res., 87, 89-100.

Metternicht, G., \& Gonzalez, S. (2004). FUERO: foundations of a fuzzy exploratory model for soil erosion hazard prediction. Environmental Modelling and Software, 20 (6), 715-728.

Minasny, B. \& McBratney, A. B. (2002). The neuro-m methods for fitting neural network parametric pedotransfer functions. Soil Sci Soc Am J., 66, 352-361.

Najafi, M., \& Givi, J. (2006). Evaluation of prediction of bulk density by artificial neural network and PTFs. 10th Iranian Soil Science Congress. Karaj., pp: 680-681. (in Persian)

Nelson, D. W. \& Sommers, L. E. (1982). Total carbon, organic carbon, and organic matter. In: Page, AL, Miller, RH, Keeney DR (Eds.), Methods of Soil Analysis. Part II, 2nd ed. American Society of Agronomy, Madison, WI, USA. pp. 539-580.

Omid, M. H., Omid, M. \& Varaki, M. E. (2005). Modeling hydraulic jumps with artificial neural networks, Proceedings of ICE-Water Management., 158(2), 65-70.

Pachepsky, Y. A. \& Rawls, W. J. (2003). Soil structure and pedotransfer functions. Eur J Soil Sci., 54, 443- 451.

Sadiq, R., \& Rodriguez, M. J. (2004). Fuzzy synthetic evaluation of disinfection by-products: a risk-based indexing system. $J$ Environ Manage, 73, 1-13.

Schaap, M. G., Leij, F. J., \& Van Genuchten, M. Th. (1998). Neural network analysis for hierarchical prediction of soil hydraulic properties. Soil Sci. Soc. Am. J., 62, 847-855.

Shuh, W. M., Cline, R. D. \& Sweeney, M. D. (1988). Comparison of a laboratory procedure and a textural model for predicting in situ water retention. Soil Sci Soc Am J., 52, 1218-1227.

Sparks, D. L., Page, A. L., Helmke, P. A., Leoppert, R. H., Soltanpour, P. N., Tabatabai, M. A., Johnston, G. T., \& Summer, M. E. (1996). Methods of soil analysis. Soil Sci. Soc. of Am. Madison, Wisconsin.

Sun, R. (2009). Data Mining Based on Fuzzy Rough Set Theory and Its Application in the Glass Identification. Modern Applied Science, 3(8), 100-105.

Sys, Ir. C., Van Ranst, E. \& Debaveye, Ir. J. (1991). Land evaluation. Part I. Principal Land evaluation and Crop production calculation general administration for development, Cooperation agric Pub., 1(7), 247pp.

Tamari, S., Wosten, J. H. M. \& Ruiz-Suarez, J. C. (1996). Testing an artificial neural network for predicting soil hydraulic conductivity. Soil Sci Soc Am J., 60, 1732-1741.

Tayfur, G., Ozdemir, S., \& Singh, V. P. (2003). Fuzzy logic algorithm for runoff-induced sediment transport from bare soil surfaces. Advances in Water Resources, 26, 1249-1256. 
Tran, L.T., Ridgley, M. A., Duckstein, L., \& Sutherland, R. (2002). Application of a fuzzy logic-based modeling to improve the performance of the revised universal soil loss equation. Catena, 47(3), 203-226.

USDA. (2010). Soil Survey Staff. Keys to Soil Taxonomy. 11 th edition.

Vos, B. D., Meirvenne, M. Quataert, V., Deckers, P. J., \& Muys, B. (2005). Predictive quality of pedotransfer functions for estimating bulk density of forest soils. Soil Sci. Soc. Am. J., 69, 500-510.

Wagner, B., Tarnawski, V. R., Hennings, V., Muller, U., Wessolek, G. \& Plagge, R. (2001). Evaluation of pedo-transfer functions for unsaturated soil hydraulic conductivity using an independent data set. Geoderma, 102, 275-279.

Wösten, J. H. M., Lilly, A., Nemes, A., \& Le Bas, C. (1999). Development and use of a database of hydraulic properties of European soils. Geoderma, 90, 169-185.

Zhang, B., Zhang, Y., Chen, D., White, R. E., \& Li, Y. (2004). A quantitative evaluation system of soil productivity for intensive agriculture in China. Geoderma, 123, 319-331.

Table 1. Example of reliability factors and effective degrees for redundant and inconsistent rules

\begin{tabular}{|c|c|c|c|c|c|}
\hline$x_{1}$ & $x_{2}$ & $y$ & Degree & $R F$ & $D_{\text {eff }}$ \\
\hline $\mathrm{A}$ & $\mathrm{B}$ & $\mathrm{C}_{1}$ & $\mathrm{D}_{1}$ & $3 / 6$ & $\mathrm{D}_{1} * 3 / 6$ \\
\hline $\mathrm{A}$ & $\mathrm{B}$ & $\mathrm{C}_{1}$ & $\mathrm{D}_{2}$ & $3 / 6$ & $\mathrm{D}_{2} * 3 / 6$ \\
\hline $\mathrm{A}$ & $\mathrm{B}$ & $\mathrm{C}_{1}$ & $\mathrm{D}_{3}$ & $3 / 6$ & $\mathrm{D}_{3} * 3 / 6$ \\
\hline $\mathrm{A}$ & $\mathrm{B}$ & $\mathrm{C}_{2}$ & $\mathrm{D}_{4}$ & $2 / 6$ & $\mathrm{D}_{4} * 2 / 6$ \\
\hline $\mathrm{A}$ & $\mathrm{B}$ & $\mathrm{C}_{2}$ & $\mathrm{D}_{5}$ & $2 / 6$ & $\mathrm{D}_{5} * 2 / 6$ \\
\hline $\mathrm{A}$ & $\mathrm{B}$ & $\mathrm{C}_{3}$ & $\mathrm{D}_{6}$ & $1 / 6$ & $\mathrm{D}_{6} * 1 / 6$ \\
\hline
\end{tabular}

Table 2. Statistics of training data sets for F.C and P.W.P

\begin{tabular}{|c|c|c|c|c|c|}
\hline \multirow{4}{*}{} & Soil parameter & Min & Max & Mean & Std \\
\cline { 2 - 6 } & Clay (\%) & 4.40 & 55.60 & 22.30 & 11.83 \\
\cline { 2 - 6 } & Silt (\%) & 2.80 & 62.80 & 30.10 & 12.86 \\
\cline { 2 - 6 } & O.C (\%) & 0.04 & 1.10 & 0.35 & 0.23 \\
\cline { 2 - 6 } & $\mathrm{CaCO}_{3}(\%)$ & 2.86 & 25.4 & 10.63 & 5.92 \\
\cline { 2 - 6 } & $\mathrm{S} . \mathrm{P}(\%)$ & 21.18 & 65.67 & 34.76 & 9.26 \\
\cline { 2 - 6 } & B.D (g.cm $\left.{ }^{-3}\right)$ & 1.20 & 1.71 & 1.50 & 0.11 \\
\cline { 2 - 6 } & F.C (\%) & 10.80 & 32.50 & 17.38 & 4.65 \\
\cline { 2 - 6 } & P.W.P (\%) & 5.72 & 16.40 & 9.02 & 2.36 \\
\hline
\end{tabular}


Table 3. Statistics of testing data sets for F.C and P.W.P

\begin{tabular}{|c|c|c|c|c|c|}
\hline \multirow{4}{*}{} & Soil parameter & Min & Max & Mean & Std \\
\cline { 2 - 7 } & Clay (\%) & 17.20 & 54.80 & 29.99 & 10.49 \\
\cline { 2 - 7 } & Silt (\%) & 6.00 & 40.80 & 22.44 & 11.58 \\
\cline { 2 - 7 } & O.C (\%) & 0.19 & 0.66 & 0.38 & 0.13 \\
\cline { 2 - 7 } & $\mathrm{CaCO}_{3}(\%)$ & 11.00 & 30.20 & 17.32 & 5.01 \\
\cline { 2 - 7 } & $\mathrm{S} . P(\%)$ & 28.62 & 59.51 & 39.07 & 9.61 \\
\cline { 2 - 7 } & B.D (g.cm $\left.{ }^{-3}\right)$ & 1.26 & 1.70 & 1.46 & 0.13 \\
\cline { 2 - 6 } & F.C (\%) & 14.40 & 29.62 & 19.61 & 4.81 \\
\cline { 2 - 6 } & P.W.P (\%) & 6.81 & 15.20 & 9.96 & 2.63 \\
\hline
\end{tabular}

Table 4. Simple linear correlation coefficients (r) among F.C, P.W.P and independent variables

\begin{tabular}{|c|c|c|c|c|c|c|c|c|}
\hline & $\begin{array}{c}\text { Clay } \\
(\%)\end{array}$ & $\begin{array}{c}\text { Silt } \\
(\%)\end{array}$ & $\begin{array}{c}\text { O.C } \\
(\%)\end{array}$ & $\begin{array}{c}\mathrm{CaCO}_{3} \\
(\%)\end{array}$ & $\begin{array}{c}\text { S.P } \\
(\%)\end{array}$ & $\begin{array}{c}\text { B.D } \\
\left({\left.\mathrm{g} . \mathrm{cm}^{-3}\right)}\right.\end{array}$ & $\begin{array}{c}\text { F.C } \\
(\%)\end{array}$ & $\begin{array}{c}\text { P.W.P } \\
(\%)\end{array}$ \\
\hline Clay (\%) & 1 & & & & & & & \\
\hline Silt (\%) & 0.19 & 1 & & & & & & \\
\hline O.C (\%) & $0.09^{*}$ & $0.28^{*}$ & 1 & & & & & \\
\hline $\mathrm{CaCO}_{3}(\%)$ & $0.59^{* *}$ & -0.01 & -0.14 & 1 & & & & \\
\hline $\mathrm{S} . \mathrm{P}(\%)$ & $0.76^{* *}$ & $0.26^{*}$ & 0.18 & $0.49^{* *}$ & 1 & & & \\
\hline B.D $\left(\mathrm{g} . \mathrm{cm}^{-3}\right)$ & -0.22 & 0.05 & $-0.58^{* *}$ & -0.03 & $-0.27^{*}$ & 1 & & \\
\hline F.C (\%) & $0.75^{* *}$ & $0.28^{*}$ & 0.16 & $0.52^{* *}$ & $0.95^{* *}$ & $-0.29^{*}$ & 1 & \\
\hline P.W.P (\%) & $0.71^{* *}$ & $0.31^{*}$ & 0.13 & $0.45^{* *}$ & $0.90^{* *}$ & $-0.23^{*}$ & $0.88^{* *}$ & 1 \\
\hline
\end{tabular}

* significant at the 0.05 level

** significant at the 0.01 level

Table 5. Fuzzy rules relating the clay, silt, O.C, S.P, B.D and $\mathrm{CaCO}_{3}$ contents to F.C ( $\mathrm{L}=$ Low; $\mathrm{M}=$ Medium; $\mathrm{H}=$ High; V=Very)

\begin{tabular}{|c|c|c|c|c|c|c|c|c|c|c|c|c|c|c|}
\hline $\begin{array}{c}\text { Rule } \\
\text { No. }\end{array}$ & IF & $\begin{array}{c}\text { Clay } \\
(\%)\end{array}$ & and & $\begin{array}{c}\text { Silt } \\
(\%)\end{array}$ & and & $\begin{array}{c}\text { O.C } \\
(\%)\end{array}$ & and & $\begin{array}{c}C a C O_{3} \\
(\%)\end{array}$ & and & $\begin{array}{c}\text { S.P } \\
(\%)\end{array}$ & $\begin{array}{c}\text { and } \\
\left(g . \mathrm{cm}^{-3}\right)\end{array}$ & THEN & $\begin{array}{c}F . C \\
(\%)\end{array}$ \\
\hline 1 & $\mathrm{IF}$ & $\mathrm{VL}$ & and & $\mathrm{VL}$ & and & $\mathrm{VL}$ & and & $\mathrm{VL}$ & and & $\mathrm{VL}$ & and & $\mathrm{H}$ & THEN & $\mathrm{VL}$ \\
\hline 2 & $\mathrm{IF}$ & $\mathrm{VL}$ & and & $\mathrm{L}$ & and & $\mathrm{VL}$ & and & $\mathrm{VL}$ & and & $\mathrm{VL}$ & and & $\mathrm{H}$ & THEN & $\mathrm{VL}$ \\
\hline$\ldots$ & $\mathrm{IF}$ & $\ldots$ & and & $\ldots$ & and & $\ldots$ & and & $\ldots$ & and & $\ldots$ & and & $\ldots$ & THEN & $\ldots$ \\
\hline 50 & $\mathrm{IF}$ & $\mathrm{VH}$ & and & $\mathrm{M}$ & and & $\mathrm{L}$ & and & $\mathrm{H}$ & and & $\mathrm{H}$ & and & $\mathrm{M}$ & THEN & $\mathrm{H}$ \\
\hline
\end{tabular}


Table 6. Fuzzy rules relating the clay, silt, O.C, S.P, B.D and $\mathrm{CaCO} 3$ contents to P.W.P (L= Low; M= Medium; $\mathrm{H}=$ High; $\mathrm{V}=$ Very)

\begin{tabular}{|c|c|c|c|c|c|c|c|c|c|c|c|c|c|c|}
\hline $\begin{array}{c}\text { Rule } \\
\text { No. }\end{array}$ & $\mathrm{IF}$ & $\begin{array}{c}\text { Clay } \\
(\%)\end{array}$ & and & $\begin{array}{c}\text { Silt } \\
(\%)\end{array}$ & and & $\begin{array}{c}\text { O.C } \\
(\%)\end{array}$ & and & $\begin{array}{c}C a C O_{3} \\
(\%)\end{array}$ & and & $\begin{array}{c}\text { S.P } \\
(\%)\end{array}$ & $\begin{array}{c}\text { and } \\
\left(g^{-c^{-3}}\right)\end{array}$ & THEN & $\begin{array}{c}\text { P.W.P } \\
(\%)\end{array}$ \\
\hline 1 & $\mathrm{IF}$ & $\mathrm{VL}$ & and & $\mathrm{VL}$ & and & $\mathrm{VL}$ & and & $\mathrm{VL}$ & and & $\mathrm{VL}$ & and & $\mathrm{H}$ & THEN & $\mathrm{VL}$ \\
\hline 2 & $\mathrm{IF}$ & $\mathrm{VL}$ & and & $\mathrm{L}$ & and & $\mathrm{VL}$ & and & $\mathrm{VL}$ & and & $\mathrm{VL}$ & and & $\mathrm{H}$ & THEN & $\mathrm{L}$ \\
\hline$\ldots$ & $\mathrm{IF}$ & $\ldots$ & and & $\ldots$ & and & $\ldots$ & and & $\ldots$ & and & $\ldots$ & and & $\ldots$ & THEN & $\ldots$ \\
\hline 50 & $\mathrm{IF}$ & $\mathrm{VH}$ & and & $\mathrm{M}$ & and & $\mathrm{L}$ & and & $\mathrm{H}$ & and & $\mathrm{H}$ & and & $\mathrm{M}$ & THEN & $\mathrm{H}$ \\
\hline
\end{tabular}

Table 7. Statistical parameters in test stage for soil properties based on pedotransfer functions

\begin{tabular}{|c|c|c|}
\hline \multirow{2}{*}{ Statistical parameters } & \multicolumn{2}{|c|}{ Fuzzy Table Look-up Scheme } \\
\cline { 2 - 3 } & F.C (\%) & P.W.P (\%) \\
\hline RMSE & 1.65 & 1.03 \\
\hline$R^{2}$ & 0.87 & 0.83 \\
\hline
\end{tabular}

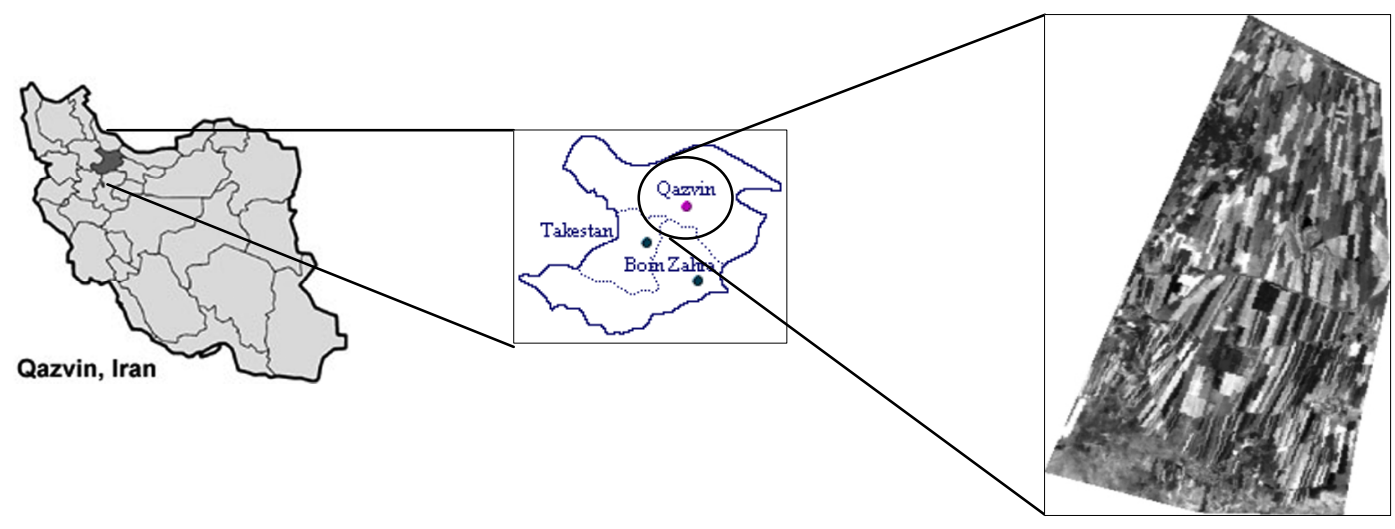

Figure 1. Location of the study area 


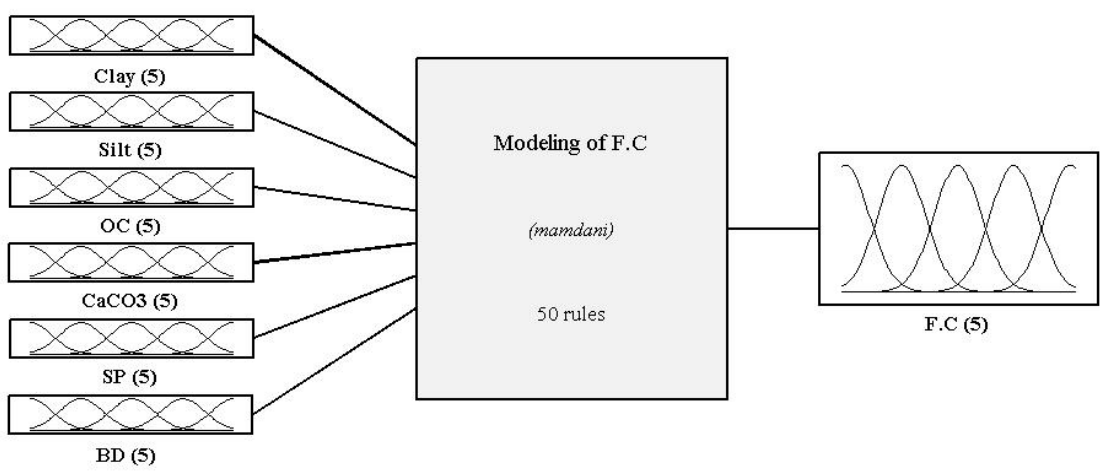

Figure 2. Structure of FIS recommended model for F.C

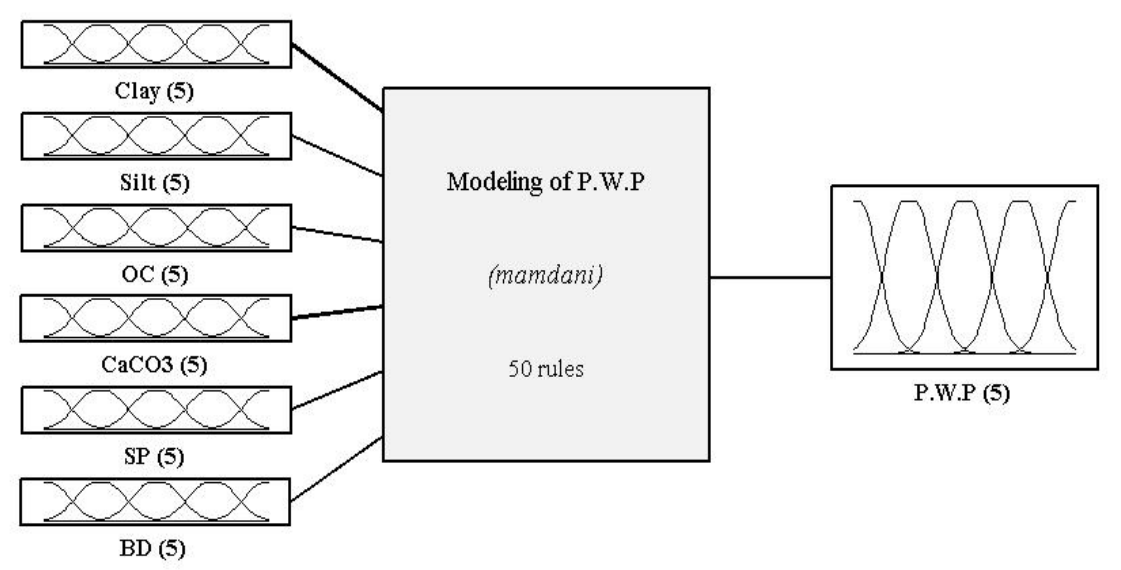

Figure 3. Structure of FIS recommended model for P.W.P

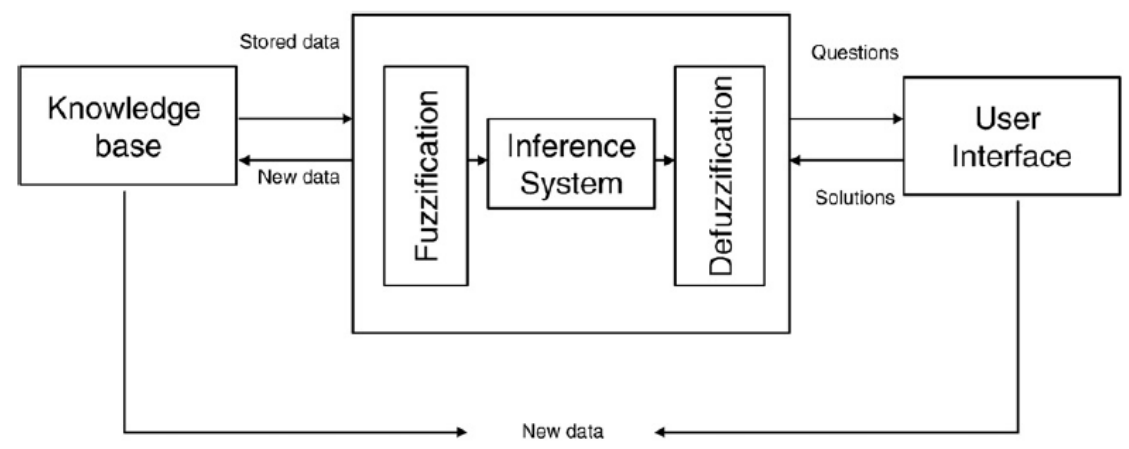

Figure 4. The general structure of the fuzzy inference system 


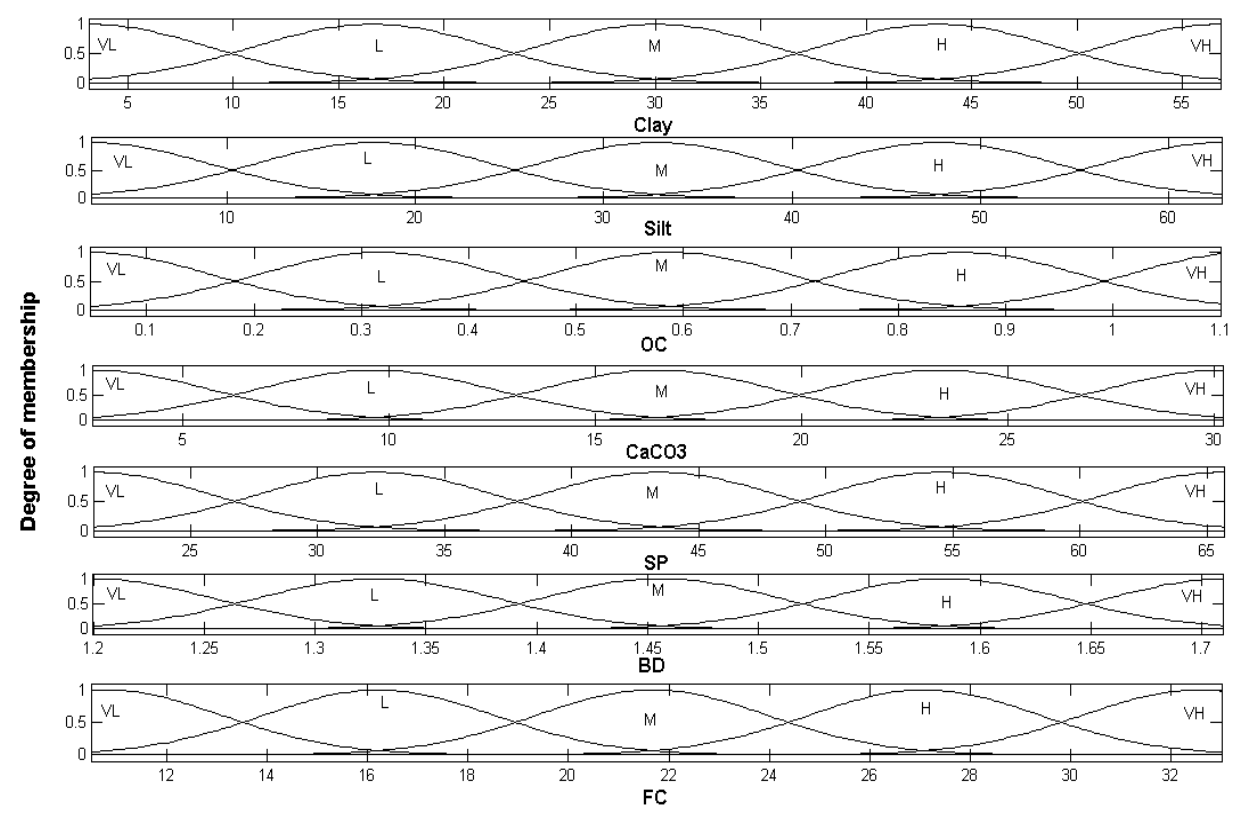

Figure 5. Fuzzy membership functions for input-output (F.C)

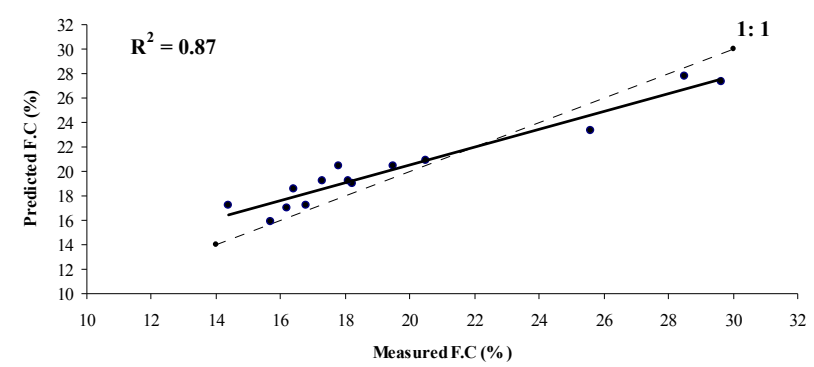

Figure 6. The scatter plot of the measured versus predicted F.C

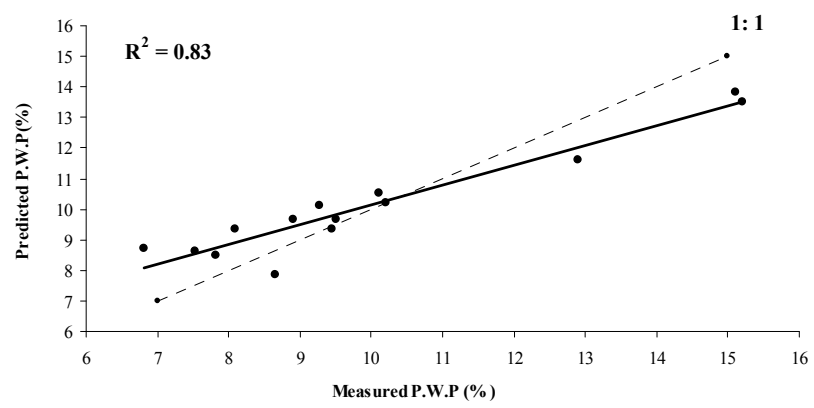

Figure 7. The scatter plot of the measured versus predicted P.W.P 